\title{
ВЛИЯНИЕ КОРОНАВИРУСНОЙ ИНФЕКЦИИ (COVID-19) НА СЕРДЕЧНО-СОСУДИСТУЮ СИСТЕМУ
}

\author{
В. Н. Ларина $凶$, М. Г. Головко, В. Г. Ларин
}

Российский национальный исследовательский медицинский университет имени Н. И. Пирогова, Москва, Россия

\begin{abstract}
Острые вирусные инфекции дыхательных путей могут увеличить вероятность прогрессирования имеющейся сопутствующей патологии, в том числе сердечно-сосудистого происхождения. Появление жизнеугрожающих осложнений на фоне коронавируса 2 (severe acute respiratory syndrome coronavirus 2, или SARS-CoV-2), вызывающего коронавирусную болезнь 2019 (Coronavirus disease 2019, или COVID-19), обусловливает необходимость изучения кардиоваскулярных эффектов COVID-19 с целью оказания рациональной медицинской помощи пациентам, особенно старшего возраста. В статье представлен обзор литературных данных, посвященных анализу клинико-функциональных особенностей пациентов с COVID-19, в том числе имевших неблагоприятный прогноз. Уделено внимание патофизиологическим особенностям, происходящим на фоне инфекционного процесса в сердечно-сосудистой системе, факторам риска и предикторам летальности при COVID-19. Обсуждается вопрос о возможности продолжения приема ингибиторов ангиотензин-превращающего фермента или антагонистов рецепторов ангиотензина II большинством пациентов с сердечно-сосудистыми заболеваниями и COVID-19
\end{abstract}

Ключевые слова: коронавирус, сердечно-сосудистые заболевания, инфекция, тяжелый острый респираторный синдром, коронавирусная болезнь 2019, ангиотензин-превращающий фермент, SARS-CoV-2, COVID-19

Благодарности: член-корреспонденту РАН, профессору, д. м. Н., профессору кафедры патофизиологии и клинической патофизиологии лечебного факультета ФГАОУ ВО РНИМУ имени Н. И. Пирогова Минздрава России Геннадию Васильевичу Порядину за ценные критические замечания.

Вклад авторов: В. Н. Ларина - разработка концепции, планирование исследования, анализ литературы, интерпретация данных, написание текста; М. Г. Головко и В. Г. Ларин - планирование исследования, анализ литературы, интерпретация данных, подготовка черновика рукописи.

$\triangle$ Для корреспонденции: Вера Николаевна Ларина

ул. Островитянова, д. 1, г. Москва, 117997; larinav@mail.ru

Статья получена: 03.04.2020 Статья принята к печати: 17.04.2020 Опубликована онлайн: 18.04.2020

DOI: $10.24075 /$ vrgmu.2020.020

\section{POSSIBLE EFFECTS OF CORONAVURUS INFECTION (COVID-19) ON THE CARDIOVASCULAR SYSTEM}

Larina VN $\bowtie$, Golovko MG, Larin VG

Pirogov Russian National Research Medical University, Moscow, Russia

Acute viral respiratory infections can increase the risk of progression of a pre-existing condition, including a cardiovascular pathology. Life-threatening complications of Coronavirus disease 2019 (COVID-19) caused by severe acute respiratory syndrome coronavirus 2 (SARS-CoV-2) necessitate research into the cardiovascular effects of COVID-19 crucial for developing adequate treatment strategy for infected patients, especially those of advanced age. This article reviews the literature on the clinical and functional characteristics of patients with COVID-19, including those with poor outcomes. The article looks at the pathophysiological processes occurring in the cardiovascular system in the setting of SARS-CoV-2 infection, risk factors and death predictors. It also discusses continuation of therapy with angiotensin-converting enzyme inhibitors and angiotensin II receptor blockers in patients with COVID-19.

Keywords: coronavirus, cardiovascular diseases, infection, severe acute respiratory syndrome, coronavirus infection 2019, angiotensin-converting enzyme, SARS-CoV-2, COVID-19

Acknowledgements: the authors thank Gennady V. Poryadin, Professor at the Department of Pathophysiology and Clinical Pathophysiology (the Faculty of General Medicine, Pirogov Russian National Research Medical University), DMSc and the correspondent member of RAS, for his invaluable critical comments on this paper.

Author contribution: Larina VN conceived and planned the study, analyzed the literature, interpreted the literature data, and revised the manuscript; Golovko MG and Larin VG planned the study, analyzed the literature, interpreted the literature data, and wrote the draft of the manuscript.

$\triangle$ Correspondence should be addressed: Vera N. Larina

Ostrovityanova, 1, Moscow, 117997; larinav@mail.ru

Received: 03.04.2020 Accepted: 17.04.2020 Published online: 18.04.2020

DOI: $10.24075 /$ brsmu.2020.020

Коронавирусы - семейство вирусов, включающее на январь 2020 г. 40 видов РНК-содержащих вирусов, объединенных в два подсемейства, которые поражают человека и животных. Геном коронавирусов (CoV) представлен одноцепочечными (+)РНК, обладающими способностью к быстрой мутации и рекомбинации. Название семейства связано со строением вируса, шиповидные отростки которого напоминают солнечную корону. Назначение «короны» у коронавирусов связано с их специфическим механизмом проникновения через мембрану клетки путем имитации «фальшивыми молекулами» молекул, на которые реагируют трансмембранные рецепторы клеток. После того как рецептор захватывает фальшивую молекулу с «короны», он продавливается вирусом в клетку, и за ним следует РНК вируса.

Острые инфекции дыхательных путей, включая грипп, респираторно-синцитиальную инфекцию, бактериальные пневмонии, являются общепризнанными триггерами сердечно-сосудистых заболеваний (СС3), а имеющиеся исходно ССЗ в свою очередь ассоциированы с другой сопутствующей патологией и могут увеличить вероятность развития и прогрессирования инфекционного процесса.

Появление тяжелого острого респираторного синдрома на фоне коронавируса 2 (severe acute respiratory syndrome coronavirus 2, или SARS-CoV-2), вызывающего коронавирусную болезнь 2019 (Coronavirus disease 2019, или COVID-19), быстро переросло в пандемию, и, как сообщалось, значительная часть пораженных вирусом пациентов имеет СС3 [1].

Проспективное когортное обсервационное исследование ARIC (atherosclerosis risk in communities study) показало, что пациенты имеют высокую вероятность развития ишемической болезни сердца (ИБС) и 
инсульта, особенно спустя 90 дней после перенесенного инфекционного процесса. Проанализировано 1312 пациентов с развитием ИБС и 712 - с инсультом, у которых в анамнезе был зафиксирован факт наличия инфекционного процесса в течение предшествующих одного-двух лет. Средний возраст пациентов составил 75 лет, среди пациентов с обострением ИБС было 57,4\% мужчин, с инсультом - 54,1\% женщин. Среди 1312 пациентов с ИБС 119 (9,1\%) имели в анамнезе госпитальную инфекцию, 366 (27,9\%) - инфекцию, развившуюся в амбулаторных условиях. Превалировали инфекции мочевыводящих путей (29\%), пневмония или респираторная инфекция (27\%), инфекция кожного покрова или подкожной клетчатки (11\%) и сепсис (8\%). Госпитальная инфекция оказалась более мощным триггером сердечно-сосудистых событий на протяжении всего периода наблюдения после перенесенной инфекции (14-й день - ОШ 12,83; 30-й день — ОШ 8,39; 42-й день — ОШ 6,24; 90-й день — ОШ $4,48)$ по сравнению с амбулаторной инфекцией $(p<0,05)$. Таким образом, категория госпитализированных пациентов с инфекционным заболеванием в анамнезе требует пристального внимания со стороны врачей и проведения своевременных мероприятий по вторичной профилактике ИБС и инсульта [2].

В связи с этим несомненный интерес вызывают патофизиологические изменения, происходящие в сердечно-сосудистой системе, в результате потенциальных эффектов коронавируса. Поскольку сведения о механизмах действия COVID-19 пока ограничены, анализ данных предыдущих исследований вспышек вирусной пневмонии и острого респираторного синдрома на Ближнем Востоке (middle east respiratory syndrome coronavirus, или MERS-CoV), а также сезонного гриппа поможет получить более полное представление о механизме действия коронавирусов на сердечно-сосудистую систему. Понимание кардиоваскулярных эффектов COVID-19 имеет важное значение для разработки и оказания своевременной комплексной медицинской помощи пациентам, особенно старшего возраста с ССЗ.

\section{Действие коронавируса на организм человека}

Коронавирусы, получившие свое название из-за характерных особенностей строения (короноподобные шипы на поверхности вируса), относят к подсемейству Coronaviridae, имеющего четыре группы: $\alpha, \beta, \gamma$ и $\delta$ CoVs по филогенетической кластеризации, из которых $\alpha$ и $\beta$ вызывают инфекцию у человека. Коронавирусы содержат четыре основных структурных белка: белок шипа (S) (обеспечивает прикрепление к рецептору клетки хозяина и последующее слияние вируса с клеточной мембраной), белок нуклеокапсида (N), белок мембраны (M) и белок оболочки (E).

Впервые коронавирус был идентифицирован у человека (HCoV) в 1965 г. в культивированных тканях трахеи человеческого эмбриона и до 2003 г. были распознаны лишь два вида HCoV: HCoV-229E и HCoV-OC43.

В настоящее время установлено, что семь разных штаммов CoV инфицируют человека, включая HCoV229E, HCoV-NL63, HCoV-OC43 и HCoV-HKU1, которые обычно вызывают саморазрешающиеся симптомы. Кроме того, коронавирус может вызывать у человека тяжелый острый респираторный синдром (ТОРС), средневосточный респираторный синдром (MERS-CoV) и летальный острый респираторный синдром, который вызывает недавно идентифицированный SARS-CoV-2.

\section{Эндемичность коронавируса}

Четыре типа HCoV, включая HCoV-229E ( $\alpha$-CoV), HCoVNL63 ( $\alpha$-CoV), HCoV-OC43 ( $\beta$-CoV) и HCoV-HKU1 ( $\beta$-CoV), эндемичны для человека и обычно вызывают легкую респираторную инфекцию с саморазрешающимися симптомами, на долю которой приходится 15-30\% острых респираторных заболеваний (ОРЗ). Как правило, данный вид инфекции встречается у лиц молодого возраста, но в старшем возрасте, особенно у пациентов, имеющих сердечно-сосудистую и бронхолегочную патологию, может служить причиной госпитализации, в том числе и экстренной [3].

\section{Тяжелый острый респираторный синдром, вызываемый коронавирусами}

Впервые вспышка SARS-CoV произошла в провинции Гуандун в южном Китае в ноябре 2002 г. [4]. Вскоре, после выделения SARS-CoV, SARS-подобные CoV были обнаружены у гималайских пальмовых цивет и енотовидных собак, причем их нуклеотидный состав на 99,8\% соответствовал составу SARS-CoV, выделенных у человека [5].

SARS-COV принадлежит $\mathrm{k}$ группе $\beta$-CoV $и$ связывается с цинковой пептидазой ангиотензинпревращающего фермента 2 (АПФ2) - поверхностной молекулой для проникновения в клетку хозяина. АПФ широко распространен в организме и представляет собой интегральный белок плазматической мембраны эндотелиальных, специализированных эпителиальных, нейроэпителиальных клеток, клеток нервных окончаний и репродуктивной системы. Физиологические функции АПФ не ограничены его ролью в регуляции функций сердечнососудистой системы. Он участвует в метаболизме ряда биологических активных пептидов и в гематопоэзе [6].

Следует отметить, что АПФ2 локализуется в эндотелиальных клетках артерий и вен, гладкой мускулатуре артериальной стенки, эпителии респираторного тракта, эпителии тонкой кишки и иммунных клетках. Подавление экспрессии АПФ2 при инфицировании SARS-CoV предположительно лежит в основе патологических изменений легочной ткани, что способствует развитию тяжелой пневмонии и острой дыхательной недостаточности.

Последующие исследования, в том числе проведенные на диких животных, доказали, что SARS-CoV мог развиваться у летучих мышей, после того как SARSподобный CoV был идентифицирован у китайских летучих мышей семейства подковоносых, имеющих высокое сходство нуклеотидных последовательностей с таковыми у SARS-CoV, выделенных от человека (87-92\%). Предположительно пальмовые циветы и енотовидные собаки выступали в роли промежуточного хозяина для амплификации SARS-CoV перед передачей его другим животным в процессе контакта с ними на рынке. Передача SARS-CoV происходит главным образом от человека $\mathrm{k}$ человеку при тесном контакте, механизм - воздушнокапельный (аэрозольно-аэрогенный).

Существует мнение о существовании и фекальноорального механизма передачи SARS-CoV-2, поскольку пациенты, зараженные SARS и MERS во время их вспышки, часто имели гастроинтестинальные симптомы в виде диареи и боли в животе, a PHK SARS-CoV была обнаружена в фекалиях у 14,6\% пациентов с SARS и MERS [7]. У некоторых пациентов заболевание начиналось 
с лихорадки и диареи до развития выраженных респираторных симптомов [8]. Исследования, проводимые in vitro, показали, что MERS-CoV может инфицировать и реплицировать в кишечном эпителии человека, действуя через рецептор дипептидилпептидазы-4. Исследования in vivo обнаружили развитие воспаления и эпителиальной дегенерации в тонком кишечнике с последующим развитием пневмонии, подтвердив, что легочная инфекция MERS-CoV была вторичной по отношению к кишечной инфекции [9].

Инкубационный период от момента контакта с заболевшим SARS-CoV-2 составляет 2-11 дней, в среднем - 5,2 (95\% ДИ 4,1-7,0) дней согласно одним данным [10], до 14 дней - согласно другим данным [11].

SARS-CoV может выделяться в окружающую среду и передаваться через руки пациентов и медицинских работников, в связи с чем необходима санитарная обработка и защита носа, рта и глаз от возможного попадания инфекции [12].

Способность зараженного пациента передавать вирус другим людям определяют по базовой оценке размножения RO. R0 для SARS-CoV составляет около 3, т. е. человек c SARS-CoV, вероятно, заразит трех других человек в восприимчивой популяции, для сравнения средняя R0 для сезонного гриппа (свиной грипп, H1N1) составляет около 1,3 [13] (табл. 1).

На сегодняшний день не существует вакцины или эффективного лекарственного препарата против SARS-CoV. Лечение TOPC включает поддерживающую симптоматическую терапию и назначение антимикробных препаратов широкого спектра действия для лечения вторичной бактериальной инфекции. Старший возраст (особенно 60 лет и старше), мультиморбидность (сахарный диабет, ССЗ, онкологические заболевания, ХОБЛ), высокий уровень лактатдегидрогеназы служат предикторами смертности при наличии SARS-CoV. Ряд авторов отмечают отсутствие значимой заболеваемости и летальности среди детей и подростков во время предыдущих вспышек SARSCoV [14].

В то же время предварительные данные о 4226 пациентах с подтвержденным диагнозом COVID-19 в CША свидетельствуют о высоком уровне смертности в группе пациентов в возрасте 85 лет и старше (10-27\%). В группе пациентов в возрасте 65-84 лет смертность составляет 3-11\%, в возрасте 55-64 лет - 1-3\%, в возрасте 2054 лет - менее 1\%, у лиц 19 лет и моложе летальных исходов установлено не было. Однако показатели общей госпитализации и госпитализации в отделение интенсивной терапии не соответствуют статистическим данным по смертности. Госпитализации были подвержены и лица более молодого возраста и 20\% смертей произошли в возрастной группе 20-64 лет, из которых 20\% составили госпитализированные пациенты 20-44 лет [15].

В настоящее время существуют лишь единичные работы, в которых освещены данные о факторах риска и предикторах летальности при COVID-19. Результаты исследования за период с 25 декабря 2019 г. по 26 января
2020 г., с участием 201 пациента, медиана возраста которых составила 51 (43-60) год (среди них 63,7\% мужчин), показали, что 32,8\% человек имели выраженную сопутствующую патологию. Медиана длительности госпитализации составила 13 (10-16) дней, 33\% пациентам потребовалась искусственная вентиляция легких (ИВЛ), а медиана времени от момента госпитализации до развития ТОРС составила 2 (1-4) дня. У большинства пациентов были выявлены отклонения со стороны лабораторных показателей: повышение уровня лактатдегидрогеназы у 98\%, С-реактивного белка (СРБ) у 85,6\%, интерлейкина-6 у 48,8\%, D-димера у 23,3\%. Возраст 65 лет и старше, нейтрофилия, органная недостаточность и нарушение гемостаза ассоциировались с развитием ТОРС и летальностью. Среди пациентов, у которых развился TOPC, назначение метилпреднизолона ассоциировалось с более низкой летальностью (46\%), чем отсутствие данного вида лечения (61,8\%) (ОШ 0,38) [16].

\section{Клинические проявления COVID-19}

Среди главных симптомов COVID-19 - лихорадка, кашель, чувство нехватки воздуха (одышка, учащенное дыхание). Реже встречаются миалгии, анорексия, тошнота, слабость, боль в горле, заложенность носа, головная боль. Симптомы могут появиться через 2 дня или к 14-му дню после контакта с заболевшим. Обнаруживаемая вирусная нагрузка одинакова у пациентов с симптомами и без симптомов COVID-19, что позволяет предполагать потенциальную возможность передачи вируса от бессимптомного или малосимптомного пациента другому человеку. Наибольшая вирусная нагрузка отмечена в области носа по сравнению с глоткой. Диагноз подтверждается с помощью полимеразной цепной реакции, материалом для которой служит соскоб со слизистой верхних и нижних дыхательных путей. Случай COVID-19 считается подтвержденным при положительном результате лабораторного исследования на наличие РНК SARS-CoV-2 независимо от клинических проявлений. Новые серологические тесты, которые удобно и возможно использовать в домашних условиях, вероятно появятся в ближайшее время.

\section{Потенциальные механизмы воздействия коронавирусной инфекции на сердечно-сосудистую систему}

Опасность ОРВИ связана с тем, что в период эпидемий значительно возрастает смертность от хронических соматических заболеваний, особенно в группе пациентов с сердечно-сосудистыми заболеваниями. Данные систематического обзора 2009 г., в который вошло 42 публикации, а также 39 клинических исследований свидетельствуют о повышении риска развития инфаркта миокарда (ОШ 4,95; 95\% ДИ 4,4-5,5) и инсульта (ОШ 3,2; 95\% ДИ 2,8-3,6) в первые дни после возникновения ОРВИ с последующим его снижением с течением времени [17].

Таблица 1. Характеристика видов коронавирусов

\begin{tabular}{|l|c|c|c|c|c|}
\hline \multicolumn{1}{|c|}{ Вид коронавируса } & Рецептор & Инкубационный период (дни) & R0 & Наличие ССЗ, \% & Уровень смертности, \% \\
\hline SARS-CoV & АПФ2 & $2-11$ & 3 & 10 & 10 \\
\hline SARS-CoV-2 & АПФ2 & $2-14$ & $2-3$ & от 3,4 $4^{*}$ до 40 $40^{* \star}$ & $0,7-8^{* \star *}$ \\
\hline
\end{tabular}

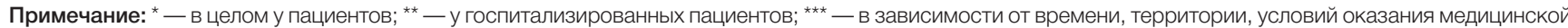
помощи. 
Гипотеза о том, что грипп может выступать в качестве провоцирующего фактора острых сердечно-сосудистых событий и летального исхода, была предложена в 1930-х гт. Тогда впервые отметили связь между сезонной активностью вируса гриппа и более высокой смертностью от всех причин, включая бронхолегочную патологию, туберкулез легких, сахарный диабет, органическую патологию сердца и геморрагический инсульт [18].

В 2004 г. был показан широкий спектр жизнеугрожающих клинических проявлений коронавирусной инфекции, включая и смерть на фоне инфаркта миокарда, который был причиной двух из пяти летальных исходов, что свидетельствует о необходимости принятия неотложных мер по лечению пациентов с ССЗ во время эпидемии вирусных инфекций [19].

Уроки предыдущих эпидемий, обусловленных коронавирусами, позволяют предположить, что вирусные инфекции могут провоцировать развитие острого коронарного синдрома, аритмий, декомпенсации сердечной недостаточности, тромбоэмболических осложнений главным образом из-за сочетания значительного системного воспалительного ответа и локализованного воспаления сосудистой стенки.

Не является исключением в этом отношении и COVID-19, который, вероятно, может изменить клинические проявления текущих ССЗ и привести к развитию дополнительных жизнеугрожающих осложнений [20].

Тяжесть и степень клинических проявлений, краткосрочные и долгосрочные сердечно-сосудистые изменения на фоне COVID-19, наряду с эффектами специфического лечения, в настоящее время не известнь и подлежат тщательному изучению. Следует отметить, что во время эпидемий гриппа большинство пациентов чаще умирает именно от сердечно-сосудистых проблем, а не от вызванной вирусом пневмонии. Учитывая мощнейшую воспалительную нагрузку, вызванную COVID-19, и ранее представленные клинические данные по другим коронавирусным инфекциям, можно ожидать значительные сердечно-сосудистые осложнения на фоне COVID-19, распространенность и выраженность которых, вероятно, будет ниже у амбулаторных, негоспитализированных пациентов.

Согласно некоторым данным [21], среди 41 госпитализированного пациента с лабораторно подтвержденным диагнозом COVID-19 в 73\% случаев были лица мужского пола, у 32\% была сопутствующая патология в виде сахарного диабета (20\%), артериальной гипертензии (АГ) (15\%), других СС3 (15\%). Медиана возраста составила 49 (41-58) лет. Наиболее частыми симптомами COVID-19 оказались лихорадка (98\%), кашель (76\%) с выделением мокроты у 28\% пациентов, миалгия или усталость (44\%), головная боль (8\%), кровохарканье (5\%), диарея (3\%). Лимфопения выявлена у 63\%, одышка у 55\% пациентов. Медиана времени от начала болезни до появления одышки составила 8 (5-13) дней. Среди осложнений, помимо ТОРС (29\%), отмечено острое поражение сердца воспалительного характера (12\%).

Исследование с участием 1099 госпитализированных пациентов и амбулаторных пациентов, которым лабораторно был подтвержден диагноз COVID-19 (медиана возраста 47 лет, из них 42\% женщин), показало, что наиболее частой сопутствующей патологией у пациентов были АГ (14,9\%), сахарный диабет $(7,4 \%)$ и ИБС $(2,5 \%)$. Наиболее серьезными осложнениями стали ТОРС (у 3,4\%) и септический шок (у 1,1\%) [22].
Вирусная инфекция и вирус-индуцированные иммунные реакции в большинстве случаев лежат в основе воспалительного процесса при миокардите. Инвазия в клетку-мишень вирусной частицы, обладающей тропностью к миокарду, прямое цитопатогенное действие вируса и включение неспецифичных механизмов противовирусной защиты (реализуемых макросрагами и NK-клетками) являются ведущими механизмами повреждения миокарда в острой фазе заболевания. Активированные макрофаги и другие клетки иммунной системы посредством продукции хемокинов привлекают в очаг воспаления Т- и В-лимфоциты. Последние реализуют механизмы клеточноопосредованного цитолиза и обеспечивают выработку противовирусных антител запускается механизм апоптоза кардиомиоцитов с дальнейшей систолической дисфункцией миокарда.

Спорадические случаи аутопсии и сообщения о случаях тяжелого миокардита с систолической дисфункцией левого желудочка после перенесенного COVID-19 позволяют предположить возможность инфильтрации миокарда интерстициальными мононуклеарными воспалительными клетками [23]. Исследования кардиальных биомаркеров указывают на высокую распространенность повреждения миокарда у госпитализированных пациентов, являющегося важнейшим прогностическим фактором при COVID-19 [24].

Миокардит представляет собой полиэтиологическое заболевание. Его причиной могут быть вирусные и бактериальные агенты, а также неинфекционные факторы. Более чем в 50\% случаев развитие миокардита обусловлено вирусами, среди которых особой кардиотропностью обладают парвовирусы В19, энтеровирусы Коксаки А и В, ECHO-вирусы, вирус краснухи, аденовирусы, вирус герпеса человека типа 6, вирус Эпштейна-Барр, цитомегаловирус, вирус гриппа и др. [25].

Клиническая картина миокардитов разнообразна и неспецифична, а их диагностика основана на триаде анамнестических данных: остром начале заболевания, связи дебюта/обострений клинических проявлений/ аритмий с инфекцией, давности менее года. К дополнительным критериям относят системные иммунные проявления, сочетание нарушений ритма и проводимости сердца, положительный эффект от стероидной терапии [26].

Опубликованы результаты наблюдения за 416 госпитализированными пациентами с COVID-19, у $57(13,7 \%)$ из которых развился летальный исход [27]. Среди этих пациентов у 10,6\% была выявлена ИБС, у 5,3\% - цереброваскулярная болезнь, у 4,1\% сердечная недостаточность, у каждого пятого пациента (20\%) - повышение уровня высокочувствительного тропонина. Пациенты с высоким уровнем тропонина были старше, имели больше коморбидных состояний, более высокий уровень лейкоцитов, натрийуретического пептида, СРБ, прокальцитонина и лимфопению, по сравнению с пациентами с нормальным значением тропопнина. У пациентов с острым повреждением сердца воспалительного генеза, в отличие от лиц без острой кардиальной патологии, чаще возникал ТОРС (58,5\% и 14,7\% соответственно; $p<0,001)$ и наступала смерть (51,2\% против 4,5\% соответственно; $p<0,001)$. Скорректированный многофакторный анализ подтвердил остро возникшую дисфункцию сердца (ОШ 4,26) и ТОРС (ОШ 7,89) в качестве предикторов неблагоприятного прогноза пациентов с COVID-19.

Аналогичные данные представлены в другом исследовании [24], согласно которому из 187 пациентов 


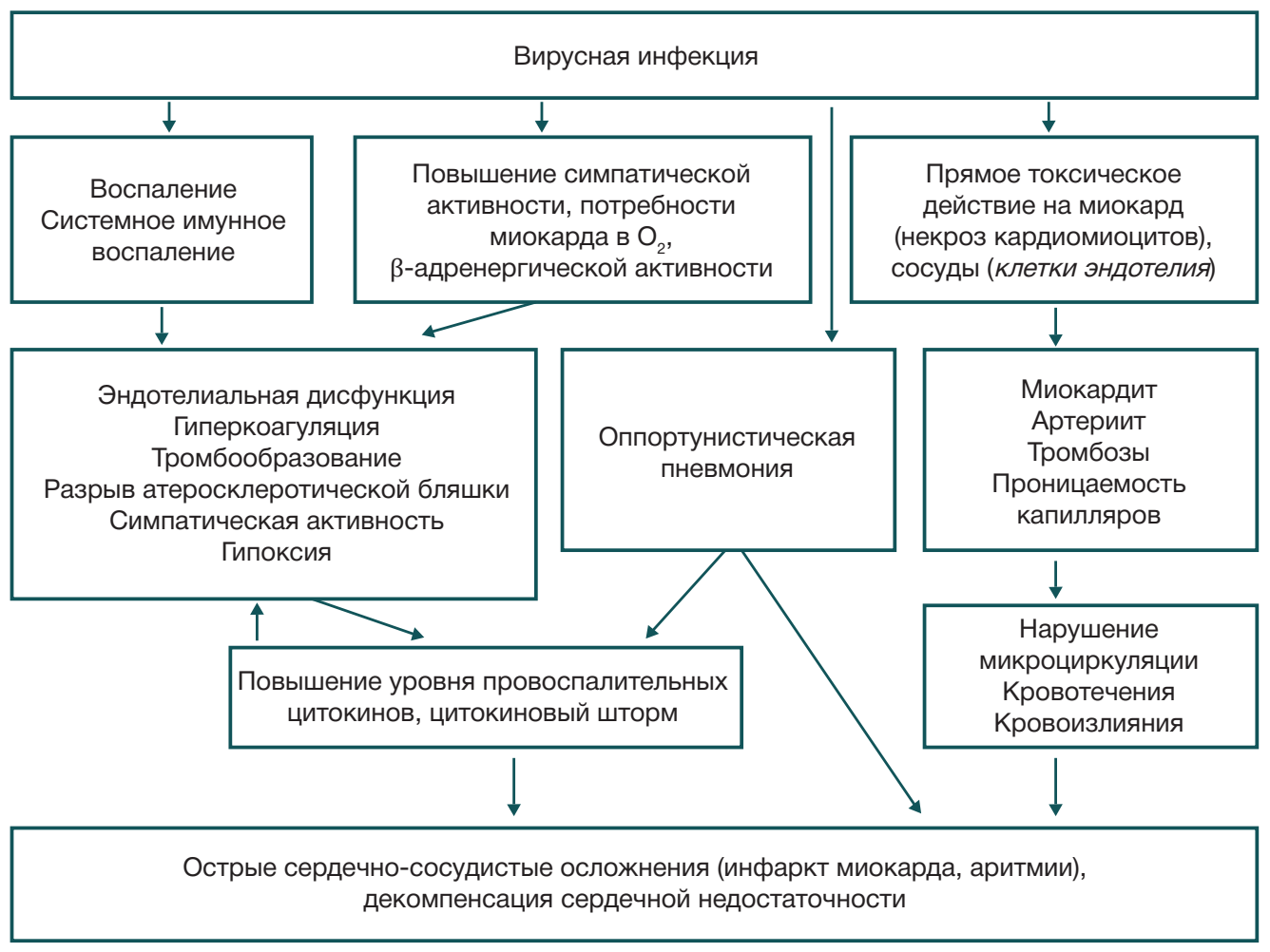

Pис. 1. Эфффекты вирусной инфекции на сердечно-сосудистую систему и миокард

с подтвержденным диагнозом COVID-19 у 27,8\% развились острые сердечно-сосудистые осложнения, приведшие к кардиальной дисфункции и нарушениям ритма, а сочетание сердечно-сосудистых осложнений с повышением высокочувствительного тропонина было связано с высокой летальностью.

Хотя точные патофизиологические механизмы, лежащие в основе миокардиального повреждения на фоне COVID-19, изучены недостаточно, существующие данные свидетельствуют о наличии генома SARS-CoV в миокарде у 35\% пациентов с ТОРС. Эти данные повышают вероятность возможного прямого повреждения кардиомиоцитов вирусами. SARS-CoV-2 может иметь тот же механизм действия, что и SARS-CoV, поскольку эти два вида вирусов очень близки, но не идентичны по геному. Наличие тесной связи высокого уровня тропонина с уровнем СРБ указывает на воспалительный генез повреждения миокарда по мере прогрессирования заболевания. Вирусные частицы, распространяясь через слизистую респираторного тракта и проникая в клетки организма, могут вызвать цитокиновый шторм за счет нарушения баланса Th1 и Th2 и серии иммунных реакций, приводящих к повреждению миокарда. Высвобождение цитокинов на фоне инфекции может вызывать снижение коронарного кровотока, доставки кислорода, дестабилизацию атеросклеротических бляшек и микротромбообразование (рис. 1).

Миокардит нередко манифестирует нарушениями ритма сердца с явлениями прогрессирующей сердечной недостаточности и внезапной сердечной смертью, способных возникнуть на любом этапе заболевания.

K первым проявлениям миокардита относят слабость, повышенную утомляемость, миалгии, изредка субфебрилитет, которые обусловлены не собственно поражением миокарда, а проявлением инфекционновоспалительного процесса. Внезапная сердечная смерть вследствие желудочковой тахикардии или фибрилляции желудочков в результате поражения миокарда в области проводящей системы сердца, тромбоэмболические осложнения, синкопальные состояния, кардиогенный шок и острая сердечная недостаточность также относят к проявлениям миокардита. Первые клинические симптомы могут возникать на фоне или спустя несколько дней после начала ОРВИ.

Современная диагностика вирусного миокардита имеет ряд трудностей. Основным диагностическим критерием миокардита являются связь кардиальных симптомов с перенесенной инфекцией и наличие признаков воспаления. В этом случае помогает комплексное клинико-лабораторное и инструментальное обследование пациента, а также проведение эндомиокардиальной биопсии по определенным показаниям для исключения воспалительной природы поражения сердца [28].

K сожалению, в настоящее время не существует доказательной базы в отношении эффективности ряда противовирусных препаратов и вакцин для COVID-19. Поскольку у пациентов с исходно имеющимися ССЗ высока вероятность развития их осложнений, более тяжелого течения заболевания и неблагоприятного исхода, целесообразна стратификация пациентов с COVID-19 в зависимости от основного CС3 и его тяжести для выбора приоритетной стратегии лечения. Электрокардиографическое исследование, определение биомаркеров сердца, таких как NT-proBNP могут быть использованы в качестве инструментов контроля за клиническим состоянием и лечением.

Противоречивым остается вопрос о продолжении приема ингибиторов ангиотензин-превращающего фермента (ИАПФ) или антагонистов рецепторов ангиотензина ॥ (AРAT-II) большинством пациентов с ССЗ. Опасения по поводу этих групп лекарственных препаратов обусловлены тем, что протеазный домен АПФ2 служит потенциальной мишенью для проникновения SARS-CoV и SARS-CoV-2 в клетки хозяина, а повышенная экспрессия АПФ2 может 


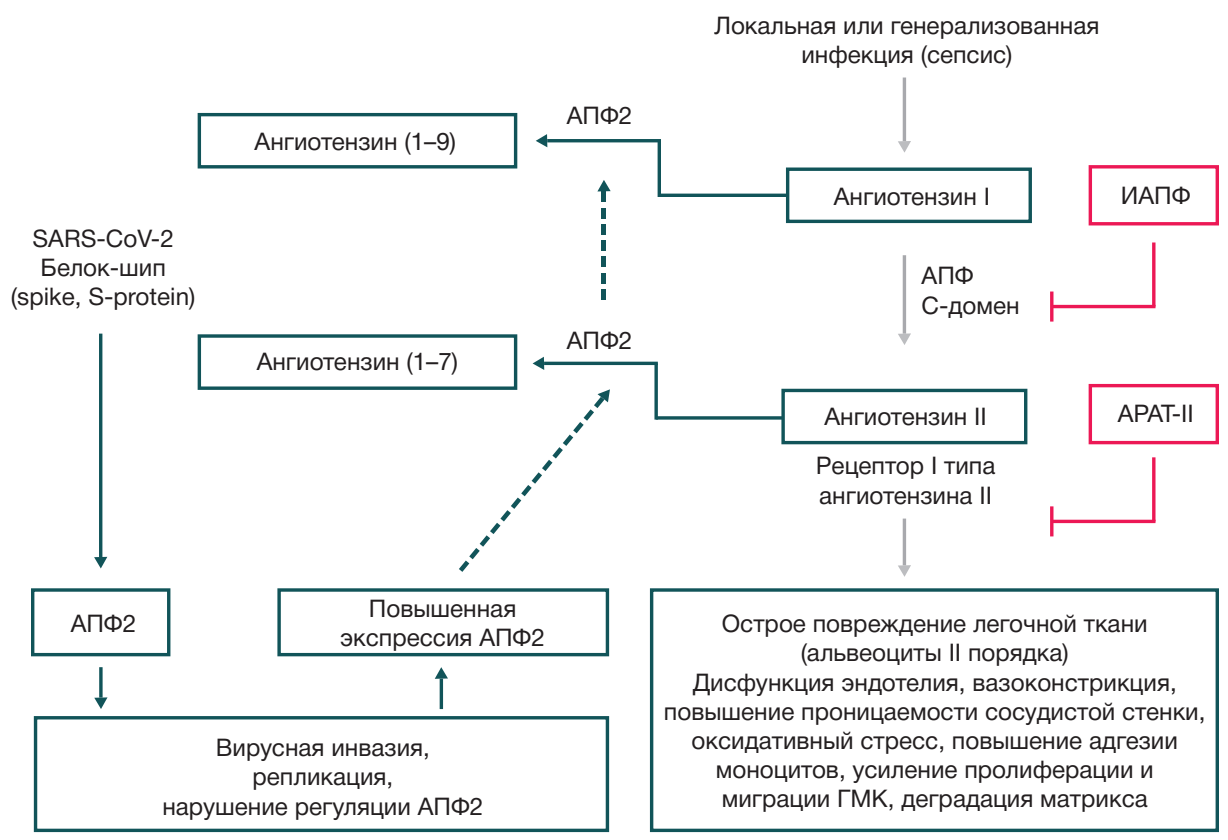

Рис. 2. Взаимодействие SARS-CoV-2 и ренин-ангиотензин-альдостероновой системы. Инвазия белка-шипа SARS-CoV-2 в клетки (в частности, альвеоциты II порядка), происходит за счет связывания с функциональным рецептором АПФ2. После эндоцитоза вирусного комплекса меняется экспрессия АПФ2, что приводит к накоплению мощнейшего вазоконстриктора ангиотензина II, и, возможно, ослаблению вазодилатирующего эффекта ангиотензина (1-7). Локальная активация системы ренин-ангиотензин-альдостерон может опосредовать реакцию повреждения легких на вирусные поражения, а повышенная экспрессия АПФ2 - усугубить повреждение легких у пациентов с COVID-19. Функция АПФ2 заключается в превращении ангиотензина I в ангиотензин (1-9) (функции изучаются) и ангиотензина II — в ангиотензин (1-7). При этом происходят инактивация ангиотензина II и синтез ангиотензина (1-7) (способствует вазодилатации, уменьшению оксидативного стресса, фиброза). АПФ - ангиотензин-превращающий фермент; ИАПФ - ингибиторы АПФ; АРАТ-І антагонисты рецепторов ангиотензина II; ГМК — гладкомышечные клетки

усугубить повреждение легких у пациентов с COVID-19 (рис. 2) (адаптировано из [29]).

Существует две формы АПФ2: в виде структурного трансмембранного белка с внеклеточным доменом, который служит мишенью для S-белка SARS-CoV-2, и растворимой - циркулирующего АПФ2. Инвазия SARS-CoV-2 в клетки, прежде всего альвеоциты II типа, происходит за счет связывания с протеазным доменом АПФ2. После эндоцитоза вирусного комплекса меняется экспрессия АПФ2, что приводит к усиленному накоплению мощнейшего вазоконстриктора ангиотензина II. Локальная активация ренин-ангиотензин-альдостероновой системы (РАAC) может опосредовать реакцию повреждения легких на вирусное поражение [30].

Ангиотензин (1-7) - субстрат N-домена АПФ, тормозит активность С-домена АПФ, ограничивая прессорное, вазоконстрикторное и другие действия АГІІ.

Клиническая роль этого процесса в развитии осложнений COVID-19 и любой эффект от возможной модуляции рецептора АПФ2 не совсем ясны и должны быть проверены в клинических исследованиях как человеческого рекомбинантного АПФ2 (NCT04287686), так и других препаратов.

Показано, что в группе пациентов с COVID-19 и высоким уровнем тропонина продолжение приема ИАПФ/АРАТ-ІІ в связи с исходно имеющимися ССЗ не влияло на уровень смертности пациентов [22]. В другом исследовании был получен положительный эффект ИАПФ/ APAT-II у пациентов с вирусной пневмонией, поскольку они значительно уменьшали воспалительную реакцию и выброс провоспалительных цитокинов, вызванных вирусной инфекцией [31]. Благоприятный эффект ИАПФ/ APAT-II также может быть связан с компенсаторным увеличением АПФ2. Данных об использовании ИАПФ/ APAT-II у пациентов с COVID-19 пока нет и необходимы более масштабные клинические исследования.
В настоящее время, согласно позиции экспертов Европейского общества кардиологов [32], Американской ассоциации сердца [33] и Российского кардиологического общества [34], пациентам с COVID-19, ранее использовавшим ИАПФ/АРА по показаниям, необходимо продолжить их прием ввиду отсутствия доказательной базы по их неэффективности у этой категории пациентов.

В настоящее время нет экспериментальных или клинических данных, демонстрирующих положительные или отрицательные результаты применения ИАПФ/АРАТII или других антагонистов PAAC у пациентов с COVID-19 или у пациентов с COVID-19 с CC3 в анамнезе. В случае если у пациентов с CC3 диагностирован COVID-19, решение о лечении должно быть принято в соответствии с индивидуальными особенностями клинической картины и гемодинамики.

Активация РАAС играет важнейшую роль в патогенезе многих ССЗ. Долгосрочные эффекты повышенной продукции ренина, ангиотензина II и активности симпатической нервной системы включают развитие гипертрофии миокарда левого желудочка, дислипидемии, нарушений ритма сердца, гиперкоагуляции, диссункции эндотелия, инсулинорезистентности, метаболического синдрома. ИАПФ и АРАТ-ІІ, изучаемые и с успехом применяемые в клинической практике на протяжении многих лет, являются препаратами первого выбора при лечении хронической сердечной недостаточности, АГ, заболеваний почек и сахарного диабета [35, 36].

Зависимое от АПФ2 проникновение SARS-CoV-2 в клетки хозяина можно блокировать мезилатом камостата, ингибитором сериновой протеазы TMPRSS2, которая используется SARS-CoV-2 для прайминга белка S. Мезилат камостата является многообещающим средством для дальнейшего тестирования [37].

Среди противогриппозных препаратов оселтамивир не влияет на SARS-CoV-2, хотя предварительные 
Таблица 2. Избранные клинические исследования лекарственных препаратов для профилактики и лечения пациентов с COVID-19

\begin{tabular}{|c|c|c|c|}
\hline Препарат & Начало изучения & $\begin{array}{l}\text { Предполагаемая } \\
\text { дата завершения }\end{array}$ & $\begin{array}{l}\text { Исследование } \\
\text { ClinicalTrials.gov }\end{array}$ \\
\hline Ремдесивир & Февраль 21, 2020 & Апрель 1, 2023 & NCT04280705 \\
\hline Рекомбинантный человеческий АПФ2 & Февраль 2020 & Апрель 2020 & NCT04287686 \\
\hline Ремдесивир & Март 2020 & Май 2020 & NCT04292899 \\
\hline $\begin{array}{l}\text { Инъекции и инфузии вакцины LV-SMENP-DS } \\
\text { и антиген-специфичных Т-киллеров }\end{array}$ & Февраль 24, 2020 & Декабрь 31, 2024 & NCT04276896 \\
\hline Финголимод & Февраль 22, 2020 & Июль 1, 2020 & NCT04280588 \\
\hline Мезенхимальные стволовые клетки человека & Февраль 24, 2020 & Февраль 1, 2021 & NCT04293692 \\
\hline Карримицин & Февраль 23, 2020 & Февраль 28, 2021 & NCT04286503 \\
\hline Метилпреднизолон & Февраль 14, 2020 & Май 30, 2020 & NCT04273321 \\
\hline Трансплантация микробиоты & Февраль 2, 2020 & Апрель 16, 2020 & NCT04251767 \\
\hline Лозартан & Март 16, 2020 & Апрель 1, 2021 & NCT04312009 \\
\hline Вакцина 2019-nCoV (mRNA-1273) & Март 3, 2020 & Июнь 1, 2021 & NCT04283461 \\
\hline Лопинавир/ритонавир в таблетках+инъекции xiyanping & Март 14, 2020 & Апрель 14, 2021 & NCT04295551 \\
\hline
\end{tabular}

исследования показали некоторую пользу от использования фавипиравира. В табл. 2 представлены некоторые препараты, изучаемые в настоящее время или находящиеся на стадии планирования их изучения у пациентов с COVID-19.

\section{ВЫВОДЫ}

Существующие данные свидетельствуют о высокой встречаемости сопутствующей патологии у пациентов с COVID-19 среднего и старшего возраста. Среди сердечнососудистых заболеваний превалируют АГ (около 15\%), сахарный диабет (7,4-20\%) и ИБС (около 2,5\%). Пациенты c COVID-19 и сердечно-сосудистой коморбидностью имеют высокую вероятность развития ТОРС, септического шока и летального исхода. Остро возникшая дисфункция сердца и ТОРС рассматриваются в качестве предикторов неблагоприятного прогноза пациентов с COVID-19.

Необходимо дальнейшее изучение особенностей скрининга, диагностики, клинических проявлений, профилактики и лечения у пациентов с COVID-19. По мере распространения болезни и появления новых данных целесообразно определить факторы риска развития сердечно-сосудистых осложнений у таких пациентов.

Возможно, что ведение регистра пациентов с COVID-19 и систематическая регистрация клинических параметров, сердечно-сосудистых и иных осложнений позволят определить современные особенности пациентов, подходы к лечению и профилактике для разработки модели риска развития осложнений.

\section{Литература}

1. Fauci AS, Lane HC, Redfield RR. Covid-19: navigating the uncharted. N Engl J Med. 2020. DOI: 10.1056/NEJMe2002387.

2. Cowan LT, Lutsey PL, Pankow JS, Matsushita K, Ishigami J, Lakshminarayan K. Inpatient and outpatient infection as a trigger of cardiovascular disease: the ARIC study. J Am Heart Assoc. 2018; 7 (22): e009683-e009683. DOI: 10.1161/ JAHA.118.009683.

3. Su S, Wong G, Shi W, et al. Epidemiology, genetic recombination, and pathogenesis of coronaviruses. Trends Microbiol. 2016; 24 (6): 490-502. DOI: 10.1016/j.tim.2016.03.003.

4. Song HD, Tu CC, Zhang GW, Wang SY, Zheng K, et al. Crosshost evolution of severe acute respiratory syndrome coronavirus in palm civet and human. Proceedings of the National Academy of Sciences. 2005; 102 (7) 2430-2435; DOI: 10.1073/ pnas.0409608102.

5. Berry M, Gamieldien J, Fielding BC. Identification of new respiratory viruses in the new millennium. Viruses. 2015; 7 (3): 996-1019. DOI: 10.3390/v7030996.

6. Nagai T, Nitta K, Kanasaki M, Kova D, Kanasaki K. The biological significance of angiotensin-converting enzyme inhibition to combat kidney fibrosis. Clin Exp Nehrol. 2015; 19 (1): 65-74.

7. Yeo C, Kaushal S, Yeo D. Enteric involvement of coronaviruses: is faecal-oral transmission of SARS-CoV-2 possible? Lancet Gastroenterol Hepatol. 2020; 5 (4): 335-7. DOI: 10.1016/S24681253(20)30048-0.

8. Assiri A, Al-Tawfiq JA, Al-Rabeeah AA, et al. Epidemiological, demographic, and clinical characteristics of 47 cases of Middle East respiratory syndrome coronavirus disease from Saudi Arabia:

a descriptive study. Lancet Infect Dis. 2013; (13): 752-61.

9. Zhou J, Li C, Zhao G, et al. Human intestinal tract serves as an alternative infection route for Middle East respiratory syndrome coronavirus. Sci Adv. 2017; (3): eaao4966.

10. Chan JF-W, Yuan S, Kok K-H, et al. A familial cluster of pneumonia associated with the 2019 novel coronavirus indicating person-to-person transmission: a study of a family cluster. Lancet. 2020; 395 (10223): 514-23. DOl: 10.1016/S0140-6736(20)30154-9.

11. Backer JA, Klinkenberg D, Wallinga J. Incubation period of 2019 novel coronavirus (2019-nCoV) infections among travellers from Wuhan, China, 20-28 January 2020. Euro Surveill. 2020; 25 (5): 2000062. DOI: 10.2807/1560-7917.ES.2020.25.5.2000062.

12. Otter JA, Donskey C, Yezli S, Douthwaite S, Goldenberg SD, Weber DJ. Transmission of SARS and MERS coronaviruses and influenza virus in healthcare settings: the possible role of dry surface contamination. J Hosp Infect. 2016; 92 (3): 235-50. DOI: 10.1016/j.jhin.2015.08.027.

13. Madjid M, Safavi-Naeini P, Solomon SD, Vardeny O. Potential Effects of Coronaviruses on the Cardiovascular System: A Review. JAMA Cardiol. Published online March 27, 2020. DOI: 10.1001/ jamacardio.2020.1286

14. Berry M, Gamieldien J, Fielding BC. Identification of new respiratory viruses in the new millennium. Viruses. 2015; 7 (3): 996-1019. DOl: 10.3390/v7030996.

15. US Centers for Disease Control and Prevention COVID-19 Response Team. Severe Outcomes Among Patients with Coronavirus Disease 2019 (COVID-19): United States, February 12-March 16, 2020. MMWR Morb Mortal Wkly Rep. Published 
online March 18, 2020. DOI: 10.15585/mmwr.mm6912e2.

16. Wu C, Chen X, Cai Y, Xia J, Zhou X, et al. Risk factors associated with acute respiratory distress syndrome and death in patients with coronavirus disease 2019 pneumonia in Wuhan, China. JAMA Intern Med. 2020 Mar 13. https://doi.org/10.1001/ jamainternmed.2020.0994.

17. C. Warren-Gash, et al. Influenza as a trigger for acute myocardial infarction or death from cardiovascular disease: a systematic review. Lancet Infect Dis. 2009; 9 (10): 601-10.

18. Collins S. Excess mortality from causes other than influenza and pneumonia during influenza epidemics. Public Health Rep. 1932; (47): 2159-89.

19. Peiris JS, Chu CM, Cheng VC, et al. HKU/UCH SARS Study Group. Clinical progression and viral load in a community outbreak of coronavirus-associated SARS pneumonia: a prospective study. Lancet. 2003; 361 (9371): 1767-72. DOI: 10.1016/S01406736(03)13412-5.

20. Kwong JC, Schwartz KL, Campitelli MA, et al. Acute myocardial infarction after laboratory-confirmed influenza infection. N Engl J Med. 2018; 378 (4): 345-53. DOI: 10.1056/NEJMoa1702090.

21. Huang C, Wang Y, Li X, et al. Clinical features of patients infected with 2019 novel coronavirus in Wuhan, China. Lancet. 2020; 395 (10223): 497-506. DOI: 10.1016/S0140-6736(20)30183-5.

22. Guan WJ, Ni ZY, Hu Y, et al. China Medical Treatment Expert Group for Covid-19. Clinical characteristics of coronavirus disease 2019 in China. N Engl J Med. 2020. DOI: 10.1056/ NEJMoa2002032.

23. Inciardi RM, Lupi L, Zaccone G, et al. Cardiac involvement 1 with coronavirus 2019 (COVID-19) infection. JAMA Cardiol. 2020. DOI: 10.1001/jamacardio.2020.1096

24. Guo T, Fan Y, Chen M, et al. Association of cardiovascular disease and myocardial injury with outcomes of patients hospitalized with 2019-coronavirus disease (COVID-19). JAMA Cardiol. Published online March 27, 2020. DOI: 10.1001/jamacardio.2020.1017.

25. Благова О. В., Недоступ А. В. Современные маски миокардита (от клинических синдромов к диагнозу). Российский кардиологический журнал. 2014; (5): 13-22. https://DOI org/10.15829/1560-4071-2014-5-13-22.

26. Благова О. В., Недоступ А. В., Коган Е. А., Седов В. П., Донников А. Е., Кадочникова В. В., и др. ДКМП как клинический синдром: результаты нозологической диагностики с применением биопсии миокарда и дифференцированного лечения у вирус- позитивных и вирус-негативных больных. Российский кардиологический журнал. 2016; (1): 7-19. https://doi.org/10.15829/1560-4071-2016-1-7-19.

27. Shi S, Qin M, Shen B, et al. Cardiac injury in patients with corona virus disease 2019. JAMA Cardiol. Published online March 25,
2020. DOI: 10.1001/jamacardio.2020.0950.

28. Cooper L, Baughman K, Feldman A, Frustaci A, Jessup M, Kuhl U, et al. The role of endomyocardial biopsy in the management of cardiovascular disease: a scientific statement from the American Heart Association, the American College of Cardiology, and the European Society of Cardiology. Endorsed by the Heart Failure Society of America and the Heart Failure Association of the European Society of Cardiology. Journal of the American College of Cardiology. 2007; 50 (19): 1914-31.

29. Vaduganathan M, Vardeny O, Michel M, McMurray J, Pfeffer M, Solomon S. Renin-Angiotensin-Aldosterone System Inhibitors in Patients with Covid-19. March 30, 2020; DOI: 10.1056/ NEJMsr2005760.

30. Bavishi C, Maddox TM, Messerli FH. Coronavirus Disease 2019 (COVID-19) Infection and Renin Angiotensin System Blockers. JAMA Cardiol. Published online April 03, 2020. DOI: 10.1001/ jamacardio.2020.1282

31. Henry C, Zaizafoun M, Stock E, Ghamande S, Arroliga AC, White HD. Impact of angiotensin-converting enzyme inhibitors and statins on viral pneumonia. Proc (Bayl Univ Med Cent). 2018; 31 (4): 41923. DOI: 10.1080/08998280.2018.1499293

32. de Simone G. Position Statement of the ESC Council on Hypertension on ACE-Inhibitors and Angiotensin Receptor Blockers. https://www.escardio.org/Councils/Council-onHypertension-(CHT)/News/position-statement-of-the-esccouncil-on-hypertension-on-ace-inhibitors-and-ang.

33. HFSA/ACC/AHA Statement Addresses Concerns Re: Using RAAS Antagonists in COVID-19. https://www.acc.org/latest-incardiology/articles/2020/03/17/08/59/hfsa-acc-aha-statementaddresses-concerns-re-using-raas-antagonists-in-covid-19.

34. Шляхто Е. В., Конради А. О., Арутюнов Г. П., Арутюнов А. Г., Баутин А. Е., Бойцов С. А., и др. Руководство по диагностике и лечению болезней системы кровообращения в контексте пандемии ООУЮ-19. Российский кардиологический журнал. 2020; 25 (3): 3801. DOI: 10.15829/1560-4071-2020-3-3801.

35. Halliday BP, Wassall R, Lota AS, et al. Withdrawal of pharmacological treatment for heart failure in patients with recovered dilated cardiomyopathy (TRED-HF): an open-label, pilot, randomised trial. Lancet. 2019; (393): 61-73.

36. Thomsen $M$, Lewinter $C$, Køber $L$. Varying effects of recommended treatments for heart failure with reduced ejection fraction: metaanalysis of randomized controlled trials in the ESC and ACCF/ AHA guidelines. ESC Heart Failure. 2016; (3): 235-44.

37. Hoffmann M, Kleine-Weber H, Schroeder S, et al. SARS-CoV-2 cell entry depends on ACE2 and TMPRSS2 and is blocked by a clinically proven protease inhibitor. Cell. 2020; (181): 1-10. DOI: 10.1016/j.cell.2020.02.052

\section{References}

1. Fauci AS, Lane HC, Redfield RR. Covid-19: navigating the uncharted. N Engl J Med. 2020. DOI: 10.1056/NEJMe2002387.

2. Cowan LT, Lutsey PL, Pankow JS, Matsushita K, Ishigami J, Lakshminarayan K. Inpatient and outpatient infection as a trigger of cardiovascular disease: the ARIC study. J Am Heart Assoc. 2018; 7 (22): e009683-e009683. DOI: 10.1161/ JAHA.118.009683.

3. Su S, Wong G, Shi W, et al. Epidemiology, genetic recombination, and pathogenesis of coronaviruses. Trends Microbiol. 2016; 24 (6): 490-502. DOI: 10.1016/j.tim.2016.03.003.

4. Song HD, Tu CC, Zhang GW, Wang SY, Zheng K, et al. Crosshost evolution of severe acute respiratory syndrome coronavirus in palm civet and human. Proceedings of the National Academy of Sciences. 2005; 102 (7) 2430-2435; DOI: 10.1073/ pnas.0409608102

5. Berry M, Gamieldien J, Fielding BC. Identification of new respiratory viruses in the new millennium. Viruses. 2015; 7 (3): 996-1019. DOI: 10.3390/v7030996.

6. Nagai T, Nitta K, Kanasaki M, Kova D, Kanasaki K. The biological significance of angiotensin-converting enzyme inhibition to combat kidney fibrosis. Clin Exp Nehrol. 2015; 19 (1): 65-74.
7. Yeo C, Kaushal S, Yeo D. Enteric involvement of coronaviruses: is faecal-oral transmission of SARS-CoV-2 possible? Lancet Gastroenterol Hepatol. 2020; 5 (4): 335-7. DOI: 10.1016/S24681253(20)30048-0

8. Assiri A, Al-Tawfiq JA, Al-Rabeeah AA, et al. Epidemiological, demographic, and clinical characteristics of 47 cases of Middle East respiratory syndrome coronavirus disease from Saudi Arabia: a descriptive study. Lancet Infect Dis. 2013; (13): 752-61.

9. Zhou J, Li C, Zhao G, et al. Human intestinal tract serves as an alternative infection route for Middle East respiratory syndrome coronavirus. Sci Adv. 2017; (3): eaao4966.

10. Chan JF-W, Yuan S, Kok K-H, et al. A familial cluster of pneumonia associated with the 2019 novel coronavirus indicating person-to-person transmission: a study of a family cluster. Lancet. 2020; 395 (10223): 514-23. DOI: 10.1016/S0140-6736(20)30154-9.

11. Backer JA, Klinkenberg D, Wallinga J. Incubation period of 2019 novel coronavirus (2019-nCoV) infections among travellers from Wuhan, China, 20-28 January 2020. Euro Surveill. 2020; 25 (5): 2000062. DOI: 10.2807/1560-7917.ES.2020.25.5.2000062.

12. Otter JA, Donskey C, Yezli S, Douthwaite S, Goldenberg SD, Weber DJ. Transmission of SARS and MERS coronaviruses and 
influenza virus in healthcare settings: the possible role of dry surface contamination. J Hosp Infect. 2016; 92 (3): 235-50. DOI: 10.1016/j.jhin.2015.08.027.

13. Madjid M, Safavi-Naeini P, Solomon SD, Vardeny O. Potential Effects of Coronaviruses on the Cardiovascular System: A Review. JAMA Cardiol. Published online March 27, 2020. DOI: 10.1001/ jamacardio.2020.1286.

14. Berry M, Gamieldien J, Fielding BC. Identification of new respiratory viruses in the new millennium. Viruses. 2015; 7 (3): 996-1019. DOI: 10.3390/v7030996.

15. US Centers for Disease Control and Prevention COVID-19 Response Team. Severe Outcomes Among Patients with Coronavirus Disease 2019 (COVID-19): United States, February 12-March 16, 2020. MMWR Morb Mortal Wkly Rep. Published online March 18, 2020. DOI: 10.15585/mmwr.mm6912e2.

16. Wu C, Chen X, Cai Y, Xia J, Zhou X, et al. Risk factors associated with acute respiratory distress syndrome and death in patients with coronavirus disease 2019 pneumonia in Wuhan, China JAMA Intern Med. 2020 Mar 13. https://doi.org/10.1001/ jamainternmed.2020.0994.

17. C. Warren-Gash, et al. Influenza as a trigger for acute myocardial infarction or death from cardiovascular disease: a systematic review. Lancet Infect Dis. 2009; 9 (10): 601-10.

18. Collins S. Excess mortality from causes other than influenza and pneumonia during influenza epidemics. Public Health Rep. 1932; (47): 2159-89.

19. Peiris JS, Chu CM, Cheng VC, et al. HKU/UCH SARS Study Group. Clinical progression and viral load in a community outbreak of coronavirus-associated SARS pneumonia: a prospective study. Lancet. 2003; 361 (9371): 1767-72. DOI: 10.1016/S01406736(03)13412-5.

20. Kwong JC, Schwartz KL, Campitelli MA, et al. Acute myocardial infarction after laboratory-confirmed influenza infection. N Engl J Med. 2018; 378 (4): 345-53. DOI: 10.1056/NEJMoa1702090.

21. Huang C, Wang Y, Li X, et al. Clinical features of patients infected with 2019 novel coronavirus in Wuhan, China. Lancet. 2020; 395 (10223): 497-506. DOI: 10.1016/S0140-6736(20)30183-5.

22. Guan WJ, Ni ZY, Hu Y, et al. China Medical Treatment Expert Group for Covid-19. Clinical characteristics of coronavirus disease 2019 in China. N Engl J Med. 2020. DOl: 10.1056/ NEJMoa2002032.

23. Inciardi RM, Lupi L, Zaccone G, et al. Cardiac involvement 1 with coronavirus 2019 (COVID-19) infection. JAMA Cardiol. 2020. DOI: 10.1001/jamacardio.2020.1096.

24. Guo T, Fan Y, Chen M, et al. Association of cardiovascular disease and myocardial injury with outcomes of patients hospitalized with 2019-coronavirus disease (COVID-19). JAMA Cardiol. Published online March 27, 2020. DOI: 10.1001/ jamacardio.2020.1017.

25. Blagova OV, Nedostup AV. Contemporary masks of the myocarditis (from clinical signs to diagnosis. Russian Journal of Cardiology. 2014; (5): 13-22. https://doi.org/10.15829/15604071-2014-5-13-22. Russian.

26. Blagova OV, Nedostup AV, Kogan EA, Sedov VP, Donnikov AV,
Kadochnikova W, et al. DCMP as a clinical syndrome: results of nosological diagnostics with myocardial biopsy and differentiated treatment in virus-positive and virus-negative patiens. Russian Journal of Cardiology. 2016; (1): 7-19. https://doi. org/10.15829/1560-4071-2016-1-7-19. Russian.

27. Shi S, Qin M, Shen B, et al. Cardiac injury in patients with corona virus disease 2019. JAMA Cardiol. Published online March 25, 2020. DOI: 10.1001/jamacardio.2020.0950.

28. Cooper L, Baughman K, Feldman A, Frustaci A, Jessup M, Kuhl U, et al. The role of endomyocardial biopsy in the management of cardiovascular disease: a scientific statement from the American Heart Association, the American College of Cardiology, and the European Society of Cardiology. Endorsed by the Heart Failure Society of America and the Heart Failure Association of the European Society of Cardiology. Journal of the American College of Cardiology. 2007; 50 (19): 1914-31.

29. Vaduganathan M, Vardeny $O$, Michel M, McMurray J, Pfeffer M, Solomon S. Renin-Angiotensin-Aldosterone System Inhibitors in Patients with Covid-19. March 30, 2020; DOI: 10.1056/ NEJMsr2005760.

30. Bavishi C, Maddox TM, Messerli FH. Coronavirus Disease 2019 (COVID-19) Infection and Renin Angiotensin System Blockers. JAMA Cardiol. Published online April 03, 2020. DOI: 10.1001/ jamacardio.2020.1282

31. Henry C, Zaizafoun M, Stock E, Ghamande S, Arroliga AC, White HD. Impact of angiotensin-converting enzyme inhibitors and statins on viral pneumonia. Proc (Bayl Univ Med Cent). 2018; 31 (4): 419 23. DOI: $10.1080 / 08998280.2018 .1499293$

32. de Simone G. Position Statement of the ESC Council on Hypertension on ACE-Inhibitors and Angiotensin Receptor Blockers. https://www.escardio.org/Councils/Council-onHypertension-(CHT)/News/position-statement-of-the-esccouncil-on-hypertension-on-ace-inhibitors-and-ang.

33. HFSA/ACC/AHA Statement Addresses Concerns Re: Using RAAS Antagonists in COVID-19. https://www.acc.org/latest-incardiology/articles/2020/03/17/08/59/hfsa-acc-aha-statementaddresses-concerns-re-using-raas-antagonists-in-covid-19.

34. Shlyakho EV, Konradi AO, Arutyunov GP, Arutyunov AG, Bautin AE, Boytsov SA, et al. Guidelines for the diagnosis and treatment of circulatory diseases in the context of the COVID-19 pandemic. Russian Journal of Cardiology. 2020; 25 (3): 3801. DOI: 10.15829/1560-4071-2020-3-3801. Russian.

35. Halliday BP, Wassall R, Lota AS, et al. Withdrawal of pharmacological treatment for heart failure in patients with recovered dilated cardiomyopathy (TRED-HF): an open-label, pilot, randomised trial. Lancet. 2019; (393): 61-73.

36. Thomsen M, Lewinter $C$, Køber L. Varying effects of recommended treatments for heart failure with reduced ejection fraction: metaanalysis of randomized controlled trials in the ESC and ACCF/ AHA guidelines. ESC Heart Failure. 2016; (3): 235-44.

37. Hoffmann M, Kleine-Weber H, Schroeder S, et al. SARS-CoV-2 cell entry depends on ACE2 and TMPRSS2 and is blocked by a clinically proven protease inhibitor. Cell. 2020; (181): 1-10. DOI: 10.1016/j.cell.2020.02.052. 